\title{
Birth Weight, Neonatal Mortality and Transition Period in Kintamani Puppy Dog Development
}

\author{
Ni Made Sawitri ${ }^{1}$, I Wayan Nico Fajar Gunawan ${ }^{2}$ and I Ketut Puja ${ }^{3 *}$ \\ ${ }^{1}$ Faculty of Veterinary Medicine, Udayana University, Bali, Indonesia: ${ }^{2}$ Veterinary Surgery and Radiology Laboratory, \\ Faculty of Veterinary Medicine, Udayana University, Bali, Indonesia: ${ }^{3}$ Veterinary Genetics and Reproduction Technology \\ Laboratory, Faculty of Veterinary Medicine, Udayana University, Bali, Indonesia \\ *Corresponding author: asubali@unud.ac.id
}

Article History: $19-621 \quad$ Received: 05-Jul-20 Revised: 05-Aug-20 Accepted: 18-Aug-20
ABSTRA C T
The observations study was performed on a total of 72 puppies born alive from 16 pregnancy bitches at Asubali breeding
kennel, Gianyar, Bali. After whelping, the total number of puppies born alive or dead within a litter, beginning the eyes
open and first respond to hear was recorded. Each puppy was identified by a colored collar. Puppies were weighed at
birth and continued until 7 day of age. Data were analyzed and presented as means and standard deviation. The
difference of sex was analyzed using A two-tailed student t-test. The result of this study showed that average weight of
the male puppies was $362.77 \pm 60.15$ gram and the female puppies were $340.44 \pm 36.48$ gram. During the first week of
life, the mortality rate was $9.72 \%$. The puppy's eyes open at an age 10 to 15 day and begins to hear at an age 19 to 23
days. Birth weight and neonatal mortality was significantly affected by sex. Its concluded that the mortality rate neonatal
was low in Kintamani dog.

Key words: Birth weight, Mortality, Puppy, Kintamani.

C2020 IJVS - All Rights Reserved

\section{INTRODUCTION}

The Federation Cynologique Internationale (FCI), is an international federation of several national kennel clubs, was recognized fully 346 official breeds in the world. Each of them is the property of a specific country. Most of this breed come from western countries. In Indonesia two breed was identified like Kintamani dog and Tengger dogs but none of these are internationally recognized. Kintamani Dog is a group of local types of mountain dogs that live around Sukawana village, in Bali. This excellent dog group is very popular and attracts a lot of attention and is in demand by dog lovers in Indonesia. Kintamani dog was considered a descendent from Balinese ferral dog with loss of genetic diversity and efforts are being made to help it attain recognition by the FCI (Puja et al. 2005). Unlike other recognized breed dogs, which have had breeding standards, especially in terms of maintenance instructions in the early period, there are no instructions in the Kintamani dogs that can be used as guidelines for the maintenance of Kintamani dogs. As a part of standardizing, improve and optimize breeding, increased knowledge about reproductive parameters is essential. Hence, this cross-sectional study was conducted to record the body weight of new born and neonatal mortality and transition period development of Kintamani dogs.

The newborn puppies, in continuing their life processes are very dependent on it a dam for survival. The newborn pups need warmth, food, and protection during the first week to several weeks of their lives. During this time, their sensory capabilities are not yet fully developed, so they are completely dependent on their mother's care (Howell et al. 2015). The first week to two weeks or neonatal period in the life of the puppy has limited ability in movement. Two weeks until the puppy is approximately 3 weeks of age is determining as transition period. During the transitional period there is changes in structural and functional systems of the animal (Ogbu et al. 2016). Eyeopening at approximately 13 days of age marks the start of the transition period, which ends when the ear channels open (Grandjean 2003).

In neonatal period, the death both during parturition and in the neonatal period is significant occurs in puppies. In dogs, the mortality rate in the neonatal period can reach $17-30 \%$ and the highest mortality rate generally occurs in the first week of life (Lawer et al. 2008; Vassalo et al. 2015).

Cite This Article as: Sawitri NM, Gunawan IWNF and Puja IK, 2021. Birth weight, neonatal mortality and transition period in Kintamani puppy dog development. International Journal of Veterinary Science 10(1): 43-46. https://doi.org/10.47278/journal.ijvs/2020.003 
High mortality rates in the neonatal period are associated with several factors, including low birth weight, stillbirth, neglect of the mother, lack of mother's milk and congenital conditions. However, many neonatal period deaths are also associated with poor reproductive management.

As a part of improve and optimize breeding, increased knowledge about neonatal and transtition period development in Kintamani dogs is essential. Hence, this cross-sectional study was conducted to record especially the birth weight, live born puppies of the Kintamani breed, with the aim of determining the realtionship factor sex of puppies on the birth weight, neonatal mortality, age of eyes open and age of puppies hear.

\section{MATERIALS AND METHODS}

\section{Study area and samples}

The research material consisted of 72 puppies born alive from 16 pregnancy bitches at Asubali breeding kennel, Gianyar during period from 2012-2018. All bitches clinically healthy were used in this research. The bitches were kept in individual cages in $2 \times 4 \mathrm{~m}$ and feeding of balanced commercial food. All data obtain from normal whelping, none of the whelpings were assisted.

All data concerning Birth weight of new born, sex of puppies and neonatal mortality, management and clinical information are collected from the breeder's records. The breeders also completed questions concerning any diseases and deaths of puppies from birth until they were 1 weeks of age. The body weight of each puppy was recorded by the breeder at birth, every day until the puppy was 7 days old. The beginning eyes to open was done by visual observation and the time to start listening is done with the Key test.

\section{Statistical analysis}

Data on birth weight, weight at the age of 7 days and mortality, beginning the eyes open and first respond to hear was presented descriptively. The relationship between puppy sex with birth weight, mortality and time to open eyes, the time to start respond was analyzed by the $\mathrm{T}$ test (Heat 2000) using the SPSS program ver.17 for window.

\section{RESULTS}

A total number of 72 Kintamani puppies born normally from 16 pregnancy bitches. Based on sex, there were 38 males and 34 females. The average birth weight of male Kintamani dogs is $362.77 \pm 60.15 \mathrm{~g}$ and for the female weight is average of $340.44 \pm 36.48 \mathrm{~g}$. The results of the weighing on the $7^{\text {th }}$ day showed $522.60 \pm 82.24 \mathrm{~g}$ in males while $509.11 \pm 50.56 \mathrm{~g}$ in females. The results on the $7^{\text {th }}$ day showed an average increase in body weight for male puppies of $\pm 159.83 \mathrm{~g}$ and females $\pm 168.67 \mathrm{~g}$ with a significant difference in birth weight between male and female puppies $(\mathrm{P}<0.05)$.

During the first 3 weeks of life, mortality rate of live born puppies was $9,72 \%$. One puppy was stilborn. One puppy died at the age of 2 days, two puppies died at four days of age, two puppies died at the age of 5 days, and one puppy died at age six days (Table 1). Six puppies died after birth identified that was caused by Fading puppy syndrome. The puppies had signs consistent with unusual restlessness with persistent crying, forced respiration, poor sucking response and generalized weakness. The dead puppies were six female and one male. The analysis results showed that there was a significant relationship between sex and mortality of Kintamani puppies in the neonatal period $(\mathrm{P}<0.05)$.

Table 1: Causes of death of a puppy before seven days

\begin{tabular}{|c|c|c|c|c|c|c|c|}
\hline \multirow[t]{2}{*}{ Causes } & \multicolumn{7}{|c|}{ Time of Death of Puppy } \\
\hline & Day- & Day- & Day- & Day- & Day- & Day- & Day- \\
\hline Born dead & 1 & & & & & & \\
\hline Diarrhea & & & & & & & \\
\hline Trauma & & & & & & & \\
\hline Low body weight & & & & & & & \\
\hline $\begin{array}{l}\text { Fading puppy } \\
\text { syndrome }\end{array}$ & & 1 & & 2 & 2 & 1 & \\
\hline Unknown & & & & & & & \\
\hline
\end{tabular}

The results of the study of eye-opening time in Kintamani puppies were found the eyes opened on the $10^{\text {th }}$ day to the $15^{\text {th }}$ day with the average at $12.27 \pm 1.20$ days for males and 13.1013.10 \pm 1.23 days for females. The results of the statistical analysis did not show any significant differences between female puppies and males ( $\mathrm{P}>0.05)$.

The results of the study on the first time of puppies began to respond sounds was found that the puppies started to respond sound on the 19th day to the 23rd day, with the average male at $20.38 \pm 0.87$ days and the female puppies at $20.93 \pm 1.06$ days. The results of the statistical analysis did not show a significant difference between the females and males $(\mathrm{P}>0.05)$.

\section{DISCUSSION}

All puppies in this study were born normally. The average birth weight of Kintamani puppies was in ideal weigh for males was $362.77 \pm 60.15$ grams and females $340.44 \pm 36.48$ grams. The average birth weight excess of male puppies is 22.33 grams. The results of this study are in accordance with the results of a study in Mudhol Hound breed and Boxer breed were male puppies is heavier than female puppies (Bigliardi et al. 2013; Dodamani et al. 2017). Birth weight was influence by sexes and male puppies tend to heavier than female puppies. This supposed caused by muscle mass in male puppies as a result of male hormones (Groppetti et al. 2017).

The deaths of Kintamani puppies in the neonatal period were $7(9.72 \%)$ of 72 puppies born. One was stillborn, and six puppies died after normal birth. This incidence of death was smaller compared to the mortality rate in other breeds. The incidence of neonatal mortality in Kintamani puppies is lower than in Mudhol Hound. The incidence of death in Hound Mudhol puppies was $10.67 \%$ (Dodamani et al. 2017). In other report, the highest incidence of perinatal death was equal to $23.3 \%$ (Mila et al 2015). The incidence of mortality in the neonatal period reached $10.9 \%$ in four large breeds of dogs (Indrebo et al. 2007) and $15 \%$ of puppies die during a week after born (Hopper et al. 2004; Hozyen et al. 2019). These show that the first week after birth is a critical period of puppy's life. The low incidence of death in Kintamani puppies is likely due to proper maintenance management or genetic factors. Adaptation of life at the time in the uterus and after born as well as the provision of colostrum is a critical period in newborn puppies. 
Six puppies died after normal birth due to weight loss as a result of poor sucking. Puppies that died after normal birth supposed as a Fading puppy syndrome. The cause of Fading puppy syndrome was probably due to congenital abnormalities and low birth weight. Previous studies have shown that mortality in the neonatal period is related to the age of the bitches, the number of puppies born and the dog breed (Tonnessen et al. 2012). In this study, there were no identified other factors than Fading puppy syndrome. The death of puppies after the second day was related to the growth rate of puppies and it is determined by the colostrum given from the dam (Mila et al. 2015). Fading puppy syndrome considered the most critical factor that causes neonatal death (Dodamani et al. 2017).

The fat content in newborn puppies is very low at around $1.3 \%$ (Kienzle et al. 1998). This fat is an energy source for puppies through the process of glycogenesis. Decreased glycogen levels in muscle and liver occur rapidly in puppies. At the same time, thermogenesis has not occurred in puppies until the age of 6 days (Munnich and Kuchenmeister 2014). This causes puppies to be vulnerable to hypoglycemia and hypothermia. As a result, the puppies will die.

The occurrence of weight loss in puppies who died on the second and fourth days, possibly related to colostrum and nutrient intake. This specific mammary secretion in the first week provides puppies passive immunity. Colostrum contains immunoglobulin which can be absorbed quickly in the small intestine a few hours post partum. Immunoglobulin absorption in the small intestine is minimum 12 hours after birth (Bouchard et al. 1992). Inadequate intake of milk can cause a lack of colostrum received by puppies. As a result, it is likely to cause a reduction in puppy's immunity. Colostrum has been known to play a vital role in early growth and neonatal death, especially in other animals. In 2 days-old piglets, colostrum intake is related to body temperature and glucose concentration. This shows that colostrum is associated with body temperature regulation and glucose balance (Devillers et al. 2011). As a result of imbalances in temperature and glucose levels can cause death in puppies. The ability of a puppy to maintain the balance of temperature and glucose levels in the body is very low; therefore, the occurrence of hypothermia and hypoglycemia is fatal in puppies (Munnich and Kuchenmeister 2014).

Inadequate nutrient intake also causes little energy reserves. Energy requirements for neonatal period puppies are very high. When energy intake is low, and the liver cannot metabolize nutrients to produce energy, this can cause puppies suffered hypoglycemia (Indrebo et al. 2007). The cause does not want to sucking probably due to congenital abnormalities and low birth weight.

The period since the puppy is born until the age of 3 weeks; the sensory organs have not fully developed. Puppies depend entirely on their mother's care. During this period, puppy's eyes began to open, although their eyesight was still limited (Howell et al. 2015). The eyes of the Kintamani puppy were opened on day 12 in males and day 13 in females range from 10 to 14 days. The average eyeopening in Kintamani puppies was not much different from other breeds of dogs. Eye openings in Kintamani puppies were in the same range when compared to German
Shepherd puppies. In German Shepherd puppies, eyes open from the age of 10 to 15 days. The Beginning time of eyes open in Kintamani puppies was in the normal range. The puppy's eyes were open for the first time at around two weeks of age. which is quite in line with what other investigators have reported (Pirrone et al. 2018).

Similar to the condition of the eyes that are closed at birth, dogs are also deaf or unable to hear perfectly because the ear canals is closed. In Kintamani puppies, they begin to respond to sounds at the age of 19 to 23 days. At this age, Kintamani puppies have begun to respond to sound. At the age of 3 weeks, the puppies can begin bonding with other dogs and people around them and recognize the features of the environment in where they live.

\section{Conclusion}

The average birth weight of Kintamani puppies is male $362.77 \pm 60.15$ grams and the birth weight of female puppies with an average of $340.44 \pm 36.48$ grams. The incidence of death of the neonatal Kintamani puppy is $9.72 \%$. Mostly cause by Fading puppy syndrome. Sex was related to birth weight and mortality. Kintamani puppies begin to open their eyes on age tenth to the fifteenth days with the average at 12.27 days for males and 13.10 days for females. Whereas starting to respond to sounds on day 19 to day 23, with the average for males at $20.38 \pm 0.87$ days and in female at $20.93 \pm 1.06$.

\section{Acknowledgements}

The authors thanks to Staff of Veterinary Genetics and Reproduction Technology Laboratory, Faculty of Veterinary Medicine, Udayana University, and also to the Asubali Kennel owners, Gianyar. who contributed to this study.

\section{REFERENCES}

Bigliardi E, Di Ianni F, Parmigiani E, Morini G and Bresciani C, 2013. Physiological weight loss in newborn puppies of boxer breed. Italian Journal of Animal Science 12: e77.

Bouchard G, Plata-Madrid H, Youngquist RS, Buening GM, Ganjam VK, Krause GF, Allen GK and Paine AL,1992. Absorption of an alternate source of immunoglobulin in pups. American Journal of Veterinary Research 53: 230-233.

Devillers N, Le Dividich J and Prunier A, 2011. Influence of colostrum intake on piglet survival and immunity. Animal 5: 1605-1612. https://doi.org/10.1017/S175173111100067X

Dodamani MS, Krishnaswamy A, Honnappagol SS, Yathiraj S, Narayanswamy M, Sudha G and Chandrashekarmurthy V, 2017. Birth weight, litter size, sex ratio and neonatal mortality in purebred Mudhol Hounds. International Journal of Science and Environment Technology 6: 2307-2317.

Grandjean D, 2003. Royal Canin German Shepherd Encyclopedia (Encyclopaedia). Aniwa Publishing, Paris, France.

Groppetti D, Pecile A, Palestrini C, Marelli SP and Boracchi P, 2017. A national census of birth weight in purebred dogs in Italy. Animals (Basel) 7: 43.

Heat D, 2000. An Introduction to Experimental Design and Statistics for Biology. UCL Press. London.

Hopper BJ, Richardson JL and Lester NV, 2004. Spontaneous antenatal resolution of canine hydrops fetalis diagnosed by ultrasound. Journal of Small Animal Practice 45: 2-8. https://doi.org/10.1111/j.1748-5827.2004.tb00187.x

Howell T J, King T and Bennett PC, 2015. Puppy parties and beyond: the role of early age socialization practices on adult 
Int J Vet Sci, 2021, 10(1): 43-46.

dog behavior. Veterinary Medicine Research Reports 6: $143-153$

Hozyen HF, AA El Shamy and AA Farghali, 2019. In vitro supplementation of nano selenium minimizes freeze-thaw induced damage to ram spermatozoa. International Journal of Veterinary Science 8: 249-254.

Indrebo A, Trangerud C and Moe L, 2007. Canine neonatal mortality in four large breeds. Acta Veterinaria Scandinavica 49 (Suppl 1): S2.

Kienzle E, Zentek J and Meyer H, 1998. Body composition of puppies and young dogs. Journal of Nutrition 128: 2680S2683S.

Lawer DF, 2008. Neonatal and pediatric care of the puppy and kitten. Theriogenology 70: 1424-1430. https://doi.org/ 10.1016/j.theriogenology.2008.04.019

Mandouh MI, Elbanna RA and Abdellatif HA, 2020. Effect of multi-species probiotic supplementation on growth performance, antioxidant status and incidence of diarrhea in neonatal Holstein dairy calves. International Journal of Veterinary Science 9: 249-253. https://doi.org/10.37422/ IJVS/20.007

Mila H, Grellet A, Feugier A and Chastant-Maillard S, 2015. Differential impact of birth weight and early growth on neonatal mortality in puppies. Journal of Animal Science 93: 4436-4442. https://doi.org/10.2527/jas.2015-8971
Munnich A and Kuchenmeister U, 2014. Causes, diagnosis and therapy of common diseases in neonatal puppies in the first days of life: Cornerstones of practical approach. Reproduction in Domestic Animal 49: 64-74. https://doi.org/10.1111/ rda. 12329

Ogbu KI, Ochai SO, Danladi MMA, Abdullateef MA, Agwu EO and Gyengdeng JG, 2016. A review of Neonatal mortality in Dogs, International Journal of Life Science 4: 451-460.

Pirrone F, Pierantoni L, Albizzati V and Albertini M, 2018. Different dynamics of sensory-motor development and behavior during the transitional period. In: Puppies: Preliminary Results. Mac Veterinary Review, 41: 153-161.

Puja IK, Irion DN, Schaffer AL and Pedersen NC, 2005. The Kintamani dog: genetic profile of an emerging breed from Bali, Indonesia. Journal of Heredity 96: 854-859.

Tonnessen R, Sverdrup Borge K, Nodtvedt A and Indrebo A, 2012. Canine perinatal mortality: a cohort study of 224 breeds. Theriogenology 77: 1788-1801. https://doi.org/ 10.1016/j.theriogenology.2011.12.023

Vassalo F G, Simoes CRB, Sudano MJ, Prestes NC, Lopes MD, Chiacchio SB and Lourenço MLG, 2015. Topics in the routine assessment of newborn puppy viability. Topics in Companion Animal Medicine 30: 16-21. https://doi.org/ $\underline{10.1053 / \text { j.tcam.2015.02.003 }}$ 